\title{
Clinical study on the changes of lung-specific proteins: CC16 after lung contusion
}

\author{
MENG-NI WEN ${ }^{1}$, GANG ZHAO ${ }^{1}$, JIA-YING ZHANG ${ }^{2}$ and YONG-HONG ZHAO ${ }^{3}$ \\ Departments of ${ }^{1}$ Emergency, ${ }^{2}$ Radiology and ${ }^{3}$ Thoracic Surgery, The Affiliated Sixth People's Hospital \\ of Shanghai Jiao Tong University, Shanghai 200233, P.R. China
}

Received February 3, 2017; Accepted May 12, 2017

DOI: $10.3892 /$ etm.2017.4842

\begin{abstract}
The aim of the present study was to examine the clinical value of continuously monitoring serum CC16 levels in diagnosing pulmonary contusion, estimating its severity degree and predicting disease progression. Thirty-one acute trauma patients with lung contusion diagnosed by chest computed tomography (CT) were included, and chest CT was re-examined on day 1, 3 and 7 after injury. Calculating all the contusion volume by the Siemens syngo volume calculation program, complications such as pleural effusion or atelectasis were observed and recorded. ELISA was employed to measure the levels of $\mathrm{CC} 16$ in all the patients for seven days, and another 15 serum samples were obtained from healthy volunteers to provide the reference value. Correlation analysis was further conducted for the CC16 levels and pulmonary contusion volume and its variations. Serum concentrations of CC16 in all the lung contusion patients were significantly higher than those in the controls, and reached a peak value on the first day. However, the contusion damage area shown in CT gradually increased with the occurrence of atelectasis and pleural effusion. The maximum volume of lung contusion had a positive correlation to the initial and average concentrations of $\mathrm{CC} 16$, and changes in the contusion volume were positively correlated with the initial concentration. The increased concentration of $\mathrm{CC} 16$ after lung contusion is an important reference for diagnosis, and may portend the possibility of further progress, while continuously monitoring CC16 serum levels in patients may provide the basis for clinical decision-making.
\end{abstract}

\section{Introduction}

Pulmonary contusion is a progressive pathological and physiological process (1-3). As the illness progresses, the involved damaged lung tissue increase, which may also lead to some

Correspondence to: Dr Gang Zhao, Department of Emergency, The Affiliated Sixth People's Hospital of Shanghai Jiao Tong University, 600 Yishan Road, Shanghai 200233, P.R. China

E-mail: g585gj@163.com

Key words: lung contusion, lung epithelium-specific proteins, $\mathrm{CC} 16$, atelectasis, pleural effusion related complications including pulmonary atelectasis, pleural effusion or even ARDS $(4,5)$. A single imaging examination after the trauma cannot reflect the severity of the damage, and it may take repeated computed tomography (CT) scans to monitor the progress of the illness and related complications, which, not only increases the radiation damages and costs, but also increases the probability of secondary damage for trauma patients.

Lung-specific-related protein Clara 16 (Clara cell protein, CC16) is considered a sensitive biomarker for lung injury, and the concentration changes of $\mathrm{CC} 16$ in serum has a great reference value for the diagnosis of post-traumatic pulmonary disease $(6,7)$.

In this study, by observing the changes of CC16 concentration after lung contusion, we aim to explore its relationships with the injury degree and progression of the illness.

\section{Patients and methods}

Patients. Patients ranging from 18 to 70 years were admitted to our emergency room directly after trauma (average preclinical time, $80 \mathrm{~min}$ ) with the diagnosis of lung contusion by chest CT scanning betwee August 2012 and March 2013. Patients with smoking history, chronic lung disease history and abnormal renal function were excluded from our study. Pulmonary contusion diagnostic reports were given based on medical history and imaging performances by the radiology attending doctors.

A total of 31 patients were included in the study and admitted to emergency ICU. The patients routinely registered basic information [age, gender, cause of trauma, injury severity score (ISS) and vital signs]. Included patients were reviewed with chest CT on day 3,5 and 7 as routine (slice thickness, $2 \mathrm{~mm}$; increment, $1 \mathrm{~mm}$ ). Imaging findings such as pulmonary contusion, atelectasis and pleural effusion were observed and recorded, and treatment options were adjusted based on this information. Included patients comprsed the lung construction group. In addition, 15 healthy volunteers were selected as a control group. Basic information is shown in Table I.

Collection of serum samples. Whole blood samples $(5 \mathrm{ml})$ were collected from patients directly after admission to our emergency room and the following 7 days. After standing at room temperature for $10 \mathrm{~min}$, the samples were centrifuged at $3,500 \mathrm{x} \mathrm{g}$ for $10 \mathrm{~min}$, and plasma was removed, well-labeled 
Table I. Demographic data of the enrolled patients.

\begin{tabular}{lcc}
\hline Variables & Pulmonary contusion & Healthy control \\
\hline Cases (n) & 31 & 15 \\
Age (years) & $46.29 \pm 15.19$ & $41.00 \pm 8.16$ \\
Male/female & $19 / 12$ & $10 / 5$ \\
ISS score & $24.52 \pm 8.06$ & - \\
Falling injury & 6 & 0 \\
Accident injury & 21 & 0 \\
Crush injury & 4 & 0 \\
\hline
\end{tabular}

Table II. Serum concentration of the CC16.

\begin{tabular}{lll}
$\begin{array}{l}\text { Time of } \\
\text { collection }\end{array}$ & Pulmonary contusion & Healthy control \\
\hline Initial & $26.54 \pm 9.96(\mathrm{ng} / \mathrm{ml})^{\mathrm{a}}$ & $5.02 \pm 1.73(\mathrm{ng} / \mathrm{ml})$ \\
Median (7 day) & $20.36 \pm 6.45(\mathrm{ng} / \mathrm{ml})^{\mathrm{a}}$ & $5.02 \pm 1.73(\mathrm{ng} / \mathrm{ml})$ \\
\hline
\end{tabular}

${ }^{\mathrm{a}}$ Compared with the control group, $\mathrm{p}<0.05$.

and stored at $-80^{\circ} \mathrm{C}$. Blood samples were collected once in the control group. The samples were preserved and the same concentration of CC16 as the normal reference value was obtained.

Measurement of lung-specific CC16 protein. The CC16 concentrations in the serum were measured using an enzyme-linked immunosorbent assay (ELISA) technique following the manufacturer's instructions (cat. no. 297322; R\&D Systems, Inc., Minneapolis, MN, USA).

Pulmonary contusion volume measurements. A radiologist physician input the chest CT imaging data of all patients to the Siemens volume calculation program to perform the lung contusion volume calculations.

Statistical analysis. Statistical analyses were performed using SPSS 17.0 statistical software (Chicago, IL, USA) for Windows. Continuous variables are shown by mean \pm standard deviation (SD). Two groups were compared using the t-test. One linear regression models were used for analysis of the relationship between lung contusion volumes and $\mathrm{CC} 16$. $\mathrm{P}<0.05$ was considered significant.

\section{Results}

Demographic data. We included 31 patients admitted to our emergency room with pulmonary contusion, of whom 18 patients were males and 13 patients were females; age rang, 26-78 years. ISS ranged from 16 to 38 . The main causes of injury were as follows: 21 cases were car accident injuries, 6 cases were falling injuries and 4 cases were crush injuries. All of the cases were chest trauma patients with multiple trauma injuries whose receiving time was 1-4 h. The age of

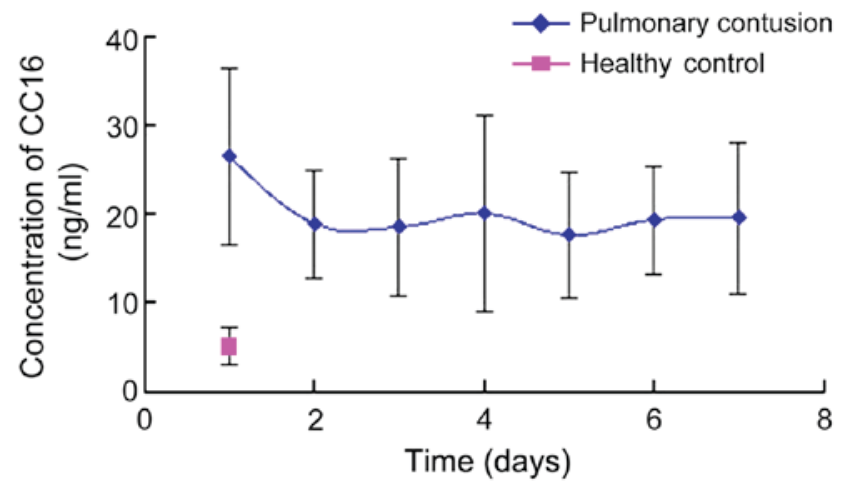

Figure 1. Changes in the serum concentration of $\mathrm{CC} 16$ for pulmonary contusion patients.

the control group ranged from 24 to 63 years, as 10 males and 5 females. The basic data are shown in Table I.

Serum concentrations of the CC16. Compared with the healthy controls, patients with pulmonary contusions showed significant elevated serum CC16 levels both at the initial and the median concentrations in the following 7 days, as shown in Table II.

Changes in the serum concentrations of CC16. The serum levels of $\mathrm{CC} 16$ were the highest on the first day after injury, decreased slightly on the second day, and maintained at a certain level in the following days, which were all higher than the normal levels (Fig. 1).

Imaging of the pulmonary contusion volume changes and complications. We found significant progresses in 11 patients when we took the second chest CT scans. Twenty-two cases (71\%) of the patients showed atelectasis on the third day, 28 (91\%) patients began to show pleural effusion in varying degrees on the third day, of which 22 cases showed lung atelectasis and pleural effusion performance at the same time (Fig. 2).

Correlation between the pulmonary contusion volume and the serum concentrations of CC16. Neither the median concentrations of CC16 levels in 7 days $(r=0.177, p=0.341)$, nor the initial serum concentration of CC16 levels $(r=0.234$, $\mathrm{p}=0.205$ ) showed correlation with the volume of contusion shown in the first CT scans. However, we observed a positive correlation between the largest volume of lung contusion during a week after injury and the $\mathrm{CC} 16$ serum levels either the median serum levels in 7 days $(r=0.498, p=0.004)$ or the initial serum levels $(r=0.538, p=0.02)$ (Figs. 3 and 4). There was no positive correlation between the initial serum levels of CC16 and the changes of pulmonary contusion volume during a week ( $\mathrm{r}=0.420, \mathrm{p}=0.019)$ (Fig. 5).

\section{Discussion}

CC16 is a type of specific-related protein that is secreted predominantly from Clara cells of the distal lung airway epithelium (8). When the Clara cells are damaged or the alveolar epithelial permeability is altered, the function of Clara cells to 

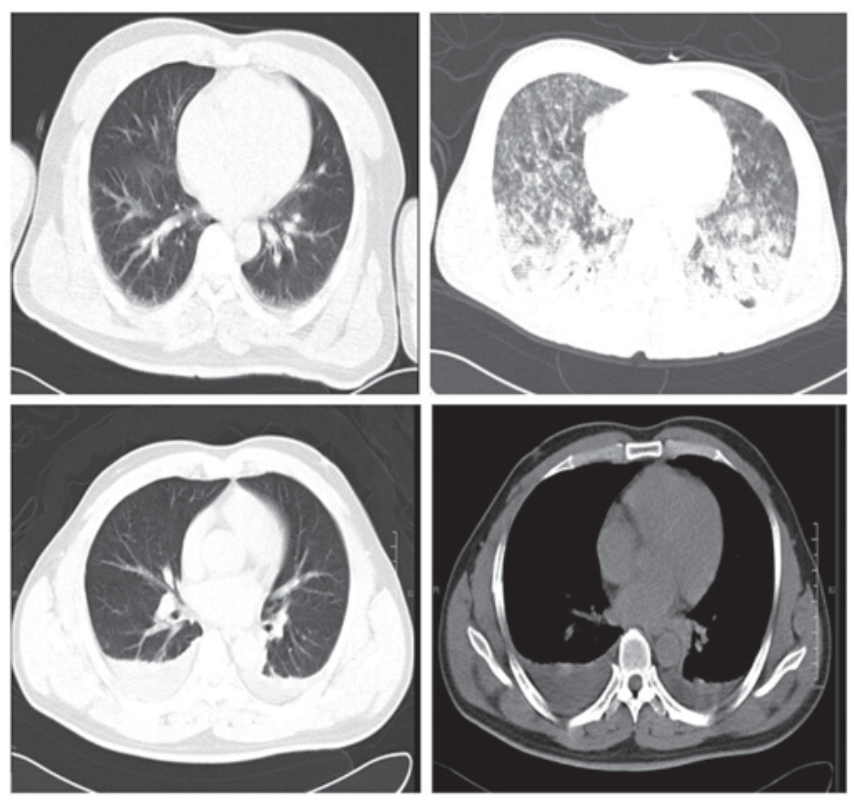

Figure 2. Typical chest CT scans for the patients. CT, computed tomography.

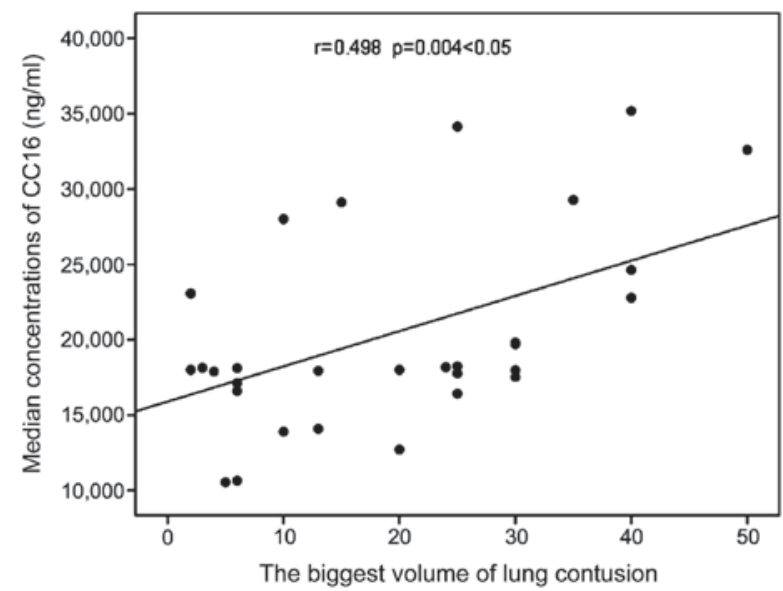

Figure 3. Correlation analysis between the largest volume of lung contusion during a week after injury and the CC16 serum levels and the median serum levels in 7 days.

synthesize and secrete CC16 is changed, which have a reference value for diagnosis of the process of the disease (9-11). Our study showed that the CC16 serum concentrations of the patients with pulmonary contusion was significantly higher than that of the healthy control group, which had certain reference value for the diagnosis of pulmonary contusion.

Pulmonary contusion is a concealed form of chest trauma, with the main pathophysiologic changes being diffuse pulmonary hemorrhage, alveolar epithelial cell injury and increased permeability of the alveolar-capillary barrier. Currently, the clinical diagnosis of pulmonary contusion is mainly based on chest CT image changes, but a single CT cannot reflect the progress or precise damage degree of the lung contusion. A study found that $30 \%$ of the patients showed increased lung contusion volumes in the later chest CT scans, while $70 \%$ of patients showed atelectasis and/or pleural effusion. However, we did not find any image information in their first chest CT

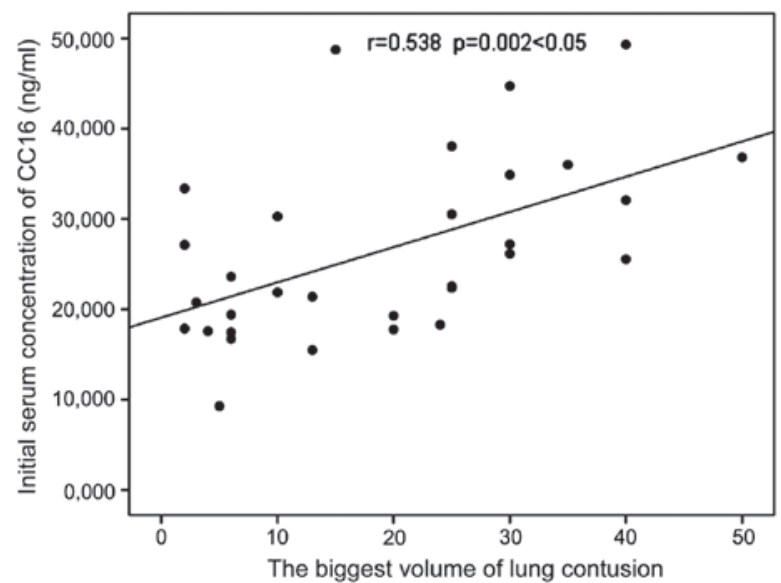

Figure 4. Correlation analysis between the largest volume of lung contusion during a week after injury and the CC16 serum levels and the initial serum levels in 7 days.

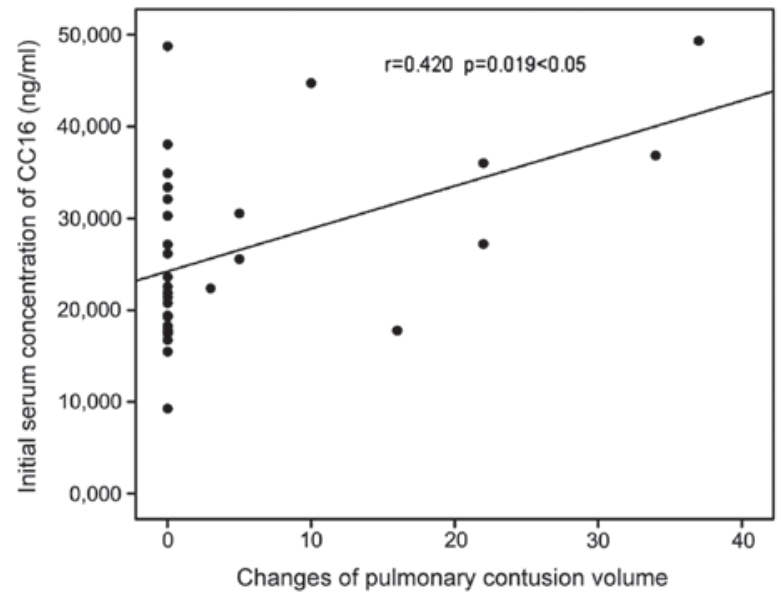

Figure 5. Correlation analysis between the changes of pulmonary contusion volume during a week and the CC16 serum levels and the initial serum levels in 7 days.

images (1). This is because the pathophysiological changes of pulmonary contusion is a transformational process (1). Progress is initiated by diffuse pulmonary hemorrhage and epithelial barrier permeability changes. At 24 h after injury, massive protein, red blood cells and inflammatory cells were identified and by $48 \mathrm{~h}$ of injury, a large amount of fibrin and cellular debris had accumulated.

This process would show the increasing lung contusion volumes and degrees on chest CT imaging. Therefore, clinicians may ignore the subsequent progression of the disease when making treatment decisions only based on the first CT findings.

Important phenomena involved some patients showing small pulmonary contusion volumes in their first CT images, while the initial CC16 concentration was relatively high. This section of disproportionate patients showed significantly increased pulmonary contusion volumes, occurring with atelectasis and pleural effusion within 3 days. Further statistical analysis showed that the maximum volume of lung contusion had a positive correlation to the initial and 
average concentrations of CC16 7 days after injury, although the initial lung contusion volume did not show this correlation. There was also a positive correlation between the initial serum levels of CC16 with the changes of pulmonary contusion volume during the period of a week. The volume of lung contusion indicates the severity of the injury. Thus, the serum concentration of $\mathrm{CC} 16$ has a positive correlation with the maximum severity of pulmonary contusion, and therefore the higher the initial CC16 concentration is, the more likely the lung contusion volume is altered.

This result suggests that the initial concentration of $\mathrm{CC} 16$ in the first $24 \mathrm{~h}$ after the injury has a reference value in the progression of pulmonary contusion. This conclusion has been proven in many other studies. For example, in a study of ventilator-associated pneumonia (12), the serum concentrations of $\mathrm{CC} 16$ showed an increase two days before pneumonia developed to ALI/ARDS. The study by Wagner and Jamieson on ARDS also found that, the higher the initial serum concentration of CC16, the worse the clinical prognosis, and the longer the application of mechanical ventilation time (13). There was also a higher risk of organ failures.

A high serum concentration of CC16 predicts a heavier contusion degree and disease development. However, the assessment of the lung contusion severity based on the first chest CT scan was not accurate, nor suitable as a basis for predicting progression of the disease. This result indicates that time is required for the process of trauma to the inflammatory infiltration to be identified on imaging scans. Additionally, damage of lung epithelial cells and barrier permeability changes in trauma occur instantaneously, causing small molecules that originally exist on the surface of the alveolar epithelium to enter into the blood circulation based on the concentration gradient more rapidly. Therefore, the blood concentrations peak rapidly, and due to changes in the synthesis and secretion function of the damaged cells, the $\mathrm{CC} 16$ concentration can be maintained at a high level. Based on these physical characteristics, CC16 has more obvious advantages as a fast and robust biomarker than imaging for lung injury clinical support monitoring of pulmonary contusion.

In conclusion, we cannot accurately assess the contusion or the process of the disease following pulmonary contusion based on a single chest CT scan and it cannot provide accurate reference for clinical treatment. $\mathrm{CC} 16$ has a reference value in the diagnosis of pulmonary contusion and monitoring of progression of the disease. Furthermore, CC16 detection is very easy and rapid, which can also reduce the secondary damage and the risk of radiation exposure for the patient due to frequent CT scans. Therefore, CC16 may serve as a biomarker to assist clinical diagnosis and monitor the progression of pulmonary contusion, which may provide a simple and effective reference basis for clinical treatment decisions.

\section{Acknowledgements}

This study was funded by Shanghai Municipal Health and Family Planning Commission (20134368).

\section{References}

1. Cohn SM and Dubose JJ: Pulmonary contusion: an update on recent advances in clinical management. World J Surg 34: 1959-1970, 2010.

2. Michalska A, Jurczyk AP, Machała W, Szram S and Berent J: Pulmonary contusion and acute respiratory distress syndrome (ARDS) as complications of blunt chest trauma. Arch Med Sadowej Kryminol 59: 148-154, 2009 (In Polish).

3. Soldati G, Testa A, Silva FR, Carbone L, Portale G and Silveri NG: Chest ultrasonography in lung contusion. Chest 130: 533-538, 2006.

4. Lemburg SP, Frangen TM, Knoop H, Nicolas V and Heyer CM: Prognostic pulmonary and thoracic findings in patients with unstable injuries of the thoracic spine. Pneumologie 65: 412-418, 2011.

5. Miller PR, Croce MA, Bee TK, Qaisi WG, Smith CP, Collins GL and Fabian TC: ARDS after pulmonary contusion: accurate measurement of contusion volume identifies high-risk patients. J Trauma 51: 223-228, 2001.

6. Broeckaert F and Bernard A: Clara cell secretory protein (CC16): characteristics and perspectives as lung peripheral biomarker. Clin Exp Allergy 30: 469-475, 2000.

7. Kropski JA, Fremont RD, Calfee CS and Ware LB: Clara cell protein (CC16), a marker of lung epithelial injury, is decreased in plasma and pulmonary edema fluid from patients with acute lung injury. Chest 135: 1440-1447, 2009.

8. Arsalane K, Broeckaert F, Knoops B, Wiedig M, Toubeau G and Bernard A: Clara cell specific protein (CC16) expression after acute lung inflammation induced by intratracheal lipopolysaccharide administration. Am J Respir Crit Care Med 161: 1624-1630, 2000.

9. Timonen KL, Hoek G, Heinrich J, Bernard A, Brunekreef B, de Hartog J, Hämeri K, Ibald-Mulli A, Mirme A, Peters A, et al: Daily variation in fine and ultrafine particulate air pollution and urinary concentrations of lung Clara cell protein CC16. Occup Environ Med 61: 908-914, 2004.

10. Dell'Omo M, Hermans C, Muzi G, Haufroid V, Bernard A, Carrieri P and Abbritti G: Serum Clara cell protein (CC16) in healthy young smokers. Biomarkers 5: 158-164, 2000.

11. McAuley DF and Matthay MA: Clara cell protein CC16. A new lung epithelial biomarker for acute lung injury. Chest 135: 1408-1410, 2009.

12. Uchida T, Shirasawa M, Ware LB, Kojima K, Hata Y, Makita K, Mednick G, Matthay ZA and Matthay MA: Receptor for advanced glycation end-products is a marker of type I cell injury in acute lung injury. Am J Respir Crit Care Med 173: 1008-1015, 2006.

13. Wagner RB and Jamieson PM: Pulmonary contusion. Evaluation and classification by computed tomography. Surg Clin North Am 69: 31-40, 1989. 